\title{
Erratum: Wave loading on rock lighthouses
}

Alison Raby, Geoffrey N. Bullock, Davide Banfi, Yaqub Rafiq and Federico Cali

An error appeared in this paper when it was published in Proceedings of the Institution of Civil Engineers - Maritime Engineering 169(1): 15-28, http://dx.doi.org/10.1680/jmaen.15. 00002.

\begin{tabular}{|c|c|c|c|c|}
\hline Date & Remarks & $\begin{array}{l}\text { No. of } \\
\text { instrument }\end{array}$ & $\begin{array}{c}\text { Pressure: } \\
\mathrm{lb} / \mathrm{ft}^{2}\end{array}$ & $\begin{array}{c}\text { Pressure: } \\
\mathrm{kN} / \mathrm{m}^{2}\end{array}$ \\
\hline \multirow[t]{2}{*}{ Jan. 7} & \multirow[t]{2}{*}{ Heavy sea } & I & 1714 & 82 \\
\hline & & $\|$ & 4182 & 200 \\
\hline \multirow[t]{2}{*}{ Jan. 12} & \multirow[t]{2}{*}{ Very heavy swell } & I & 2856 & 137 \\
\hline & & $\|$ & 5032 & 241 \\
\hline \multirow[t]{2}{*}{ Jan. 16} & \multirow{2}{*}{$\begin{array}{l}\text { Heavy ground } \\
\text { swell }\end{array}$} & I & 2856 & 137 \\
\hline & & $\|$ & 4752 & 228 \\
\hline \multirow[t]{2}{*}{ Jan. 22} & \multirow{2}{*}{$\begin{array}{l}\text { A good deal of } \\
\text { sea }\end{array}$} & I & 2856 & 137 \\
\hline & & $\|$ & 5323 & 255 \\
\hline \multirow[t]{2}{*}{ Jan. 28} & \multirow{2}{*}{$\begin{array}{l}\text { Heavy ground } \\
\text { swell }\end{array}$} & I & 2627 & 126 \\
\hline & & $\|$ & 4562 & 218 \\
\hline \multirow[t]{2}{*}{ Feb. 5} & \multirow[t]{4}{*}{ Fresh gales } & I & 856 & 41 \\
\hline & & $\|$ & 3042 & 146 \\
\hline \multirow[t]{2}{*}{ Feb. 21} & & I & 1827 & 87 \\
\hline & & $\|$ & 3422 & 164 \\
\hline \multirow[t]{2}{*}{ Feb. 24} & \multirow[t]{2}{*}{ Fresh breezes } & I & 1256 & 60 \\
\hline & & $\|$ & 3802 & 182 \\
\hline
\end{tabular}

In Table 1, the units of measurement in the fourth column should be $\mathrm{lb} / \mathrm{ft}^{2}$, not $\mathrm{kN} / \mathrm{m}^{2}$ as printed. The correct table is as follows.

Table 1. Pressure readings from Skerryvore Lighthouse in 1848

(Stevenson, 1848) 